\title{
Air Temperature Control System In Silent Generator Box
}

\section{Sistem Pengontrol Suhu Udara Pada Box Genset Silent}

\author{
Anif Saukon Kamalul Husna ${ }^{1)}$, Desriyanti ${ }^{2)}$, Rhesma Intan Vidyastari ${ }^{3)}$ \\ ${ }^{123)}$ Electrical Engineering, University Of Muhammadiyah Ponorogo, Indonesia \\ aniftezon@gmail.com ${ }^{1)}$ yunandes@gmail.com ${ }^{2)}$, rhesma.intan@gmail.com ${ }^{3)}$
}

\begin{abstract}
For the community, generators are an alternative if there is a power outage or if there is a large enough electricity demand. According to workers in the field of generator rental in Trenggalek, namely "db Genset" which has the address Ds. Gondang, Kec. Tugu, Kab. Trenggalek, there are 2 types of generators, namely open generators and silent generators, and most people choose silent generators because silent generators are specially designed to muffle engine noise so they don't cause noise, very suitable for use in active environments, but silent generators often experience temperature problems rise (Overheating) which is due to a closed engine and less smooth air circulation. Thus the cooling system on the generator set is needed to support the safety of the temperature on the silent generator so that it remains normal below $70^{\circ} \mathrm{C}$ which is important to minimize overheating problems in the silent generator, so that it can improve the performance of the generator to work for a long time without any problems. overheating. The design of the Temperature Control System in this Silent Genset Box uses Arduino Uno as a system controller and uses the Ds18b20 sensor, the engine temperature cooling process previously relied on radiator water and radiator fans, so the idea arose to add blower fans on both sides of the silent generator box, marked with a green temperature light indicator and every change in temperature will send a notification via SMS to the generator operator.
\end{abstract}

Keywords: Silent Generator; Arduino UNO; Ds18b20 Temperature Sensor; AC Fan; Indicator Light.

Abstrak-, Bagi masyarakat genset menjadi alternatif apa bila ada pemadaman listrik maupun memenuhi kebutuhan daya listrik yang cukup besar. Menurut pemaparan pekerja dalam bidang persewaan genset di Trenggalek yaitu "db Genset" yang beralamatkan Ds. Gondang, Kec. Tugu, Kab. Trenggalek,tipe genset ada 2 macam yaitu genset open dan genset silent, dan kebanyakan masyarakat memilih genset silent dikarenakan genset silent didesain khusus untuk meredam suara mesin sehingga tidak menimbulkan kebisingan sangat cocok digunakan di lingkungan yang aktif, namun genset silent sering kali mengalami kendala suhu temperatur naik (Overheating) yang dikarenakan mesin yang tertutup dan sirkulasi udara yang kurang lancar. Dengan demikian sistem pendingin pada genset sangat dibutuhkan untuk menunjang keamanan suhu pada genset silent agar tetap normal di bawah $70^{\circ} \mathrm{C}$ merupakan hal yang penting untuk meminimalisir terjadinya masalah overheating pada genset silent, sehingga bisa meningkatkan kinerja genset bekerja dalam jangka waktu yang lama tanpa ada kendala masalah overheating. Perancangan Sistem Pengontrol Suhu Pada Box Genset Silent ini menggunakan arduino uno sebagai pengendali sistem dan menggunakan sensor Ds18b20, proses pendingin suhu mesin sebelumnya mengandalkan air radiator dan kipas radiator maka timbul ide menambahkan kipas blower di kedua sisi box genset silent, dengan ditandai indikator lampu dan setiap perubahan suhu akan mengirimkan notifikasi melalui SMS kepada operator genset.

Kata kunci : Genset Silent; Arduino UNO; Sensor Suhu Ds18b20; Kipas blower; notifikasi SMS. 


\section{PENDAHULUAN}

Genset atau generator set adalah sebuah mesin yang menghasilkan listrik dengan menggunakan mesin penggerak berbahan bakar solar dan juga ada yang berbahan bakar bensin. Genset saat ini sangat dibutuhkan untuk mensuplai energi listrik dari PLN terkadang belum terpenuhi. Bagi masyarakat genset menjadi alternatif apa bila ada pemadaman listrik maupun memenuhi kebutuhan daya listrik yang cukup besar. [5]

Genset menjadi kebutuhan suatu acara, acara hajatan, pernikahan, panggung hiburan dan sebagainya dikarenakan membutuhkan energi daya listrik yang besar maka genset menjadi solusi alternatif untuk memenuhi kebutuhan energi daya listrik, dan juga genset sangat diperlukan sekolahan, rumah sakit, bank, perkantoran untuk emergency, untuk menambah energi tambahan dan cadangan apa bila ada pemadaman listrik. Tipe genset ada 2 macam yaitu genset open dan genset silent, dan kebanyakan masyarakat memilih genset silent dikarenakan genset silent didesain khusus untuk meredam suara mesin sehingga tidak menimbulkan kebisingan.[1]

\section{TINJAUAN PUSTAKA}

Pengendali suhu secara otomatis yang akan dikendalikan oleh suatu mikroprosessor berdasarkan input berupa sensor suhu LM35. Dengan adanya alat ini, keawetan alat elektronik dapat terjaga sehingga waktu pemakaian lama dan aman walaupun alat elektronik tersebut bekerja dalam waktu yang lama pula. Selain itu, pemakaian daya listrik tidak akan mengalami peningkatan.[4]

pendingin generator menggunakan Hidrogen, cara kerjanya dengan mengalirkan gas hidrogen $(\mathrm{H} 2)$ di dalam generator dan di sekitar rotor. Di dalam generator ada blower untuk menghembuskan hidrogen supaya tersebar ke seluruh bagian generator.[3]

\subsection{Genset Silent}

Genset silent adalah sebuah generator yang digerakkan oleh mesin yang berada didalam box besi yang dilapisi busa soundprofing, dan menghasilkan tegangan listrik tanpa mendengar suara mesin, sehingga genset silent sangat cocok digunakan di lingkungan yang aktif atau padat penduduk. Dimana suhu ideal temperatur mesin didalam box silent adalah $85^{\circ} \mathrm{C}$, namun mesin masih bisa bekerja hingga suhu $120^{\circ} \mathrm{C}$, apa bila suhu mesin terus meningkat sampai terlalu panas akan menyebabkan kerusakan pada komponen genset.[2]

\section{METODE PENELITIAN}

10.21070/jeeeu.v5i2.1556

Penelitian ini dalam menentukan nilai kontrol yang diuji menggunakan metode trial and erore dan metode PID tunner. Pada pengujian sistem kontrol PID menggunakan simulasi pada software Matlab.

\subsection{Perancangan Perangkat Keras}

Dalam perancangan Sistem Pengontrol Suhu Udara Pada Box Genset Silent terdiri dari Input, Kontrol, dan Output.

[Figure 1 about here.]

Dapat dijelaskan sebagai berikut:

a) Input

Sensor suhu Ds18b20 sebagai pendeteksi kelembapan dan suhu

b) Kontrol

Arduino uno berfungsi sebagai pengendali

c) Output

1. Blower kipas melancarkan sirkulasi udara

2. Buzzer sebagai indikator

3. LCD menampilkan suhu, dan tanggal

4. Lampu LED sebagai indikator

\subsection{Perancangan Perangkat Lunak}

[Figure 2 about here.]

Dari diagram flowchart tersebut dapat di jelaskan ketika mesin genset menyala suhu udara genset kurang dari $70^{\circ} \mathrm{C}$ suhu normal kipas 1 ,kipas 2 OFF, lampu hijau ON dan SIM800L mengirim SMS, dan ketika suhu udara genset lebih dari $70^{\circ} \mathrm{C}-95^{\circ} \mathrm{C}$ kemudian sensor mendeteksi suhu kemudian Mikrokontroler menerima data kemudian kipas 1 ON, buzzer ON, lampu biru ON, dan SIM800L mengirim SMS, dan ketika suhu udara genset lebih dari $95^{\circ} \mathrm{C}-120^{\circ} \mathrm{C}$ kemudian kipas 1, kipas 2, buzzer ON, lampu merah $\mathrm{ON}$, dan SIM800L mengirim SMS, dan ketika sensor mendeteksi suhu udara genset lebih dari $120^{\circ} \mathrm{C}$ mesin genset mati tetapi kipas 1 kipas 2, buzzer ON, lampu biru dan merah ON, lampu Hijau OFF sampai suhu yang berada dilam box genset silent menurun hingga $40^{\circ} \mathrm{C}$ dan lampu hijau $\mathrm{ON}$, dan begitu seterusnya. Setelah perintah selesai alat kembali seperti semula.

\section{HASIL PEMBAHASAN}

Objek penelitian prototype alat pengontrol suhu udara pada box genset silent yaitu menggunakan bahan akrilik dengan ukuran panjang $35 \mathrm{~cm}$, lebar $25 \mathrm{~cm}$, dan tinggi 20 $\mathrm{cm}$, yang berbentuk kotak balok. Bagian alat ini menjadi wadah dan body menyerupai genset silent. Data input diperoleh dari sensor suhu akan dikirimkan kepada kontroler 
yang berupa arduino uno. Data dari komponen input kemudian akan diproses untuk menyalakan kipas 1 dan 2 ketikan suhu udara dalam ruang genset silint naik dengan indikator lampu dan buzzer.

\subsection{Cara Kerja}

Menjaga suhu udara di dalam box genset silent tetap normal di bawah $70^{\circ}$ Celsius dengan menggunakan kipas sebagai alat menghisap udara dari luar box untuk mendingin kan suhu di dalam box genset silent.

\subsection{Pembuatan Prototype}

Dalam tahap ini menghasilkan pembuatan hardware berupa box dengan ukuran panjang $35 \mathrm{~cm}$, lebar $25 \mathrm{~cm}$, tinggi $20 \mathrm{~cm}$, dilengkapi dengan fentilasi udara dan kipas yang berada di kedua sisi kiri dan kanan sebagai sumber pendingin, power supply sebagai sumber tegangan 5 volt dc yang untuk men supply tegangan keseluruh rangkaian, Relay 4 chanel sebagai saklar otomatis, Arduino sebagai pengontrol sistem, Modul SD Card sebagai recod data, Lampu led dan buzzer sebagai indikator, LCD menampilkan perpindahan suhu, tanggal, jam.

[Figure 3 about here.]

\subsection{Tahap pengujian}

Pengujian ini dilakukan dengan cara mengamati kondisi prototype genset silent saat dalam keadaan suhu normal maupun tidak normal. Berikut hasil pengujian yang telah di lakukan :

[Figure 4 about here.]

[Figure 5 about here.]

[Figure 6 about here.]

[Figure 7 about here.]

[Figure 8 about here.]

[Figure 9 about here.]

[Figure 10 about here.]

[Figure 11 about here.]

[Figure 12 about here.]

[Tabel 1 about here.]

\section{KESIMPULAN}

a. Pengontrol suhu udara pada box genset silent ini menggunakan pengendali arduino yang berfungsi sebagai pengendali sistem. Beberapa komponen lain yang digunakan pada sistem pengontrol suhu ini diantaranya sensor suhu untuk mengukur temperatur suhu yang berada di dalam box genset silent, kipas 220 Volt AC sebagai sumber pendingin, Rellay chanel berfungsi sebagai saklar otomatis yang bisa dikontrol dengan arduino, modul micro SD berfungsi sebagai menyimpan data berupa tanggal, waktu, dan suhu.

b. Berdasarkan pengujian alat, indikator lampu hijau suhu berada di bawah $70^{\circ} \mathrm{C}$ menandakan suhu di dalam box normal, indikator lampu biru menandakan suhu di dalam box berada direntang suhu $70^{\circ} \mathrm{C}$ hingga $95^{\circ} \mathrm{C}$, indikator lampu merah menandakan suhu di dalam box berada direntang suhu $95^{\circ} \mathrm{C}$ hingga $120^{\circ} \mathrm{C}$, jika suhu mencapai $120^{\circ} \mathrm{C}$ mesin genset akan mati menandakan suhu di dalam box maksimal.

c. Genset akan bekerja normal kembali jika suhu menurun sampai $40^{\circ} \mathrm{C}$ dan lampu berwarna hijau sehingga lampu biru dan merah mati.

d. Modul micro SD sebagai penyimpan data, Dari proses kerja akan menginisialisasi keadaan suhu akan direkam ke dalam micro SD berupa tanggal, waktu, dan suhu. Berupa format CSV.

e. Modul SIM800L berfungsi untuk mengirimkan notifikasi perubahan suhu di dalam box berupa SMS kepada operator genset

\section{REFERENSI}

[1] Arifin, S. (2020). Jenis Genset Dan Pengertiannya. Yokyakarta: STMIK Amikom Yogyakarta.

[2] Axel Dewo Sujono, A. (2020). Kontrol Suhu Pada Generator Set Dengan Menggunakan Mikrokontroler. Jurnal Maestro Universitas Budi Luhur. Jakarta, 3.

[3] Didik Aribowo, A. R. (2013). Sistem Pendingin Generator PT Indonesia Power UPB Suralaya Menggunakan Hidrogen . Universitas Sultan Ageng Tirtayasa, 2.

[4] Martina Pineng, S. (2018). Sistem cerdas pengatur suhu secara otomatis sebagai alternatif penghematan energi listrik. Teknik Elektro UKI Toraja, Tana Toraja, 22.

[5] PT. HARTEKPRIMA LISTRINDO. (2009) Kebutuhan Genset Dan Macam Macam Jenis Genset. Surabaya. 
Journal of Electrical and Electronic Engineering-UMSIDA

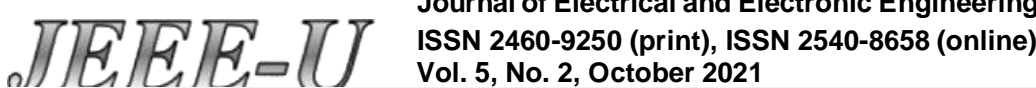

DAFTAR TABEL

Tabel 1. Hasil Pengujian. 


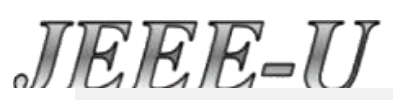 \\ Journal of Electrical and Electronic Engineering-UMSIDA \\ ISSN 2460-9250 (print), ISSN 2540-8658 (online) \\ Vol. 5, No. 2, October 2021}

10.21070/jeeeu.v5i2.1556

Tabel 1. Hasil pengujian sistem

\begin{tabular}{|c|c|c|c|c|c|c|c|}
\hline NO & Percobaan & Suhu & $\begin{array}{c}\text { Lampu } \\
\text { hijau }\end{array}$ & $\begin{array}{c}\text { Kipas 1 } \\
\text { Lampu } \\
\text { biru }\end{array}$ & $\begin{array}{c}\text { Kipas 2 } \\
\text { Lampu merah }\end{array}$ & $\begin{array}{c}\text { Mengirim } \\
\text { notifikasi } \\
\text { SMS }\end{array}$ & $\begin{array}{c}\text { Rekam data } \\
\text { Micro SD }\end{array}$ \\
\hline 1 & Percobaan 1 & $30^{\circ} \mathrm{C}$ & ON & OFF & OFF & Berhasil & Berhasil \\
\hline 2 & Percobaan 2 & $72^{\circ} \mathrm{C}$ & ON & ON & OFF & Berhasil & Berhasil \\
\hline 3 & Percobaan 3 & $95^{\circ} \mathrm{C}$ & ON & ON & OFF & Berhasil & Berhasil \\
\hline 4 & Percobaan 4 & $101^{\circ} \mathrm{C}$ & ON & ON & ON & Berhasil & Berhasil \\
\hline 5 & Percobaan 5 & $121^{\circ} \mathrm{C}$ & OFF & ON & ON & Berhasil & Berhasil \\
\hline
\end{tabular}


Daftar Gambar

Figure 1. Diagram Blok Perangkat Keras

Figure 2. Diagram alur kerja alat

Figure 3. Prototype alat

Figure 4. kondisi saat mesin nyala suhu normal di bawah $70^{\circ} \mathrm{C}$

Figure 5. Notifikasi SMS ketika suhu genset normal di bawah $70^{\circ} \mathrm{C}$

Figure 6. kondisi saat mesin nyala suhu di atas $70^{\circ} \mathrm{C}$

Figure 7. Notifikasi SMS ketika suhu genset di atas $70^{\circ} \mathrm{C}$.

Figure 8. kondisi mesin nyala suhu di atas $95^{\circ} \mathrm{C}$

Figure 9. Notifikasi SMS ketika suhu genset di atas $70^{\circ} \mathrm{C}$.

Figure 10. kondisi ketika suhu maksimal $120^{\circ} \mathrm{C}$ mesin dan lampu hijau mati

Figure 11. Notifikasi SMS ketika suhu genset di atas $120^{\circ} \mathrm{C}$ suhu maksimal

Figure 12. hasil rekam data dari micro SD dengan format CSV. 


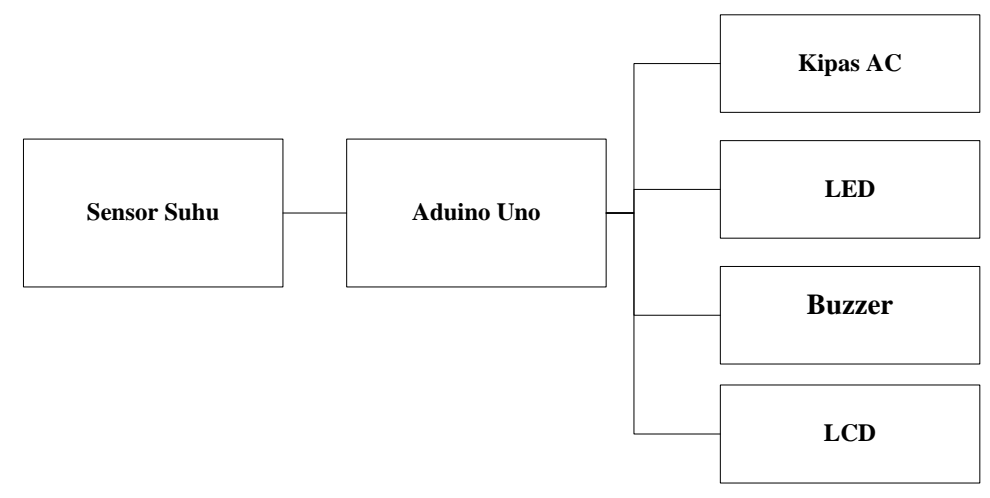

Figure 1. Diagram Blok Perangkat Keras

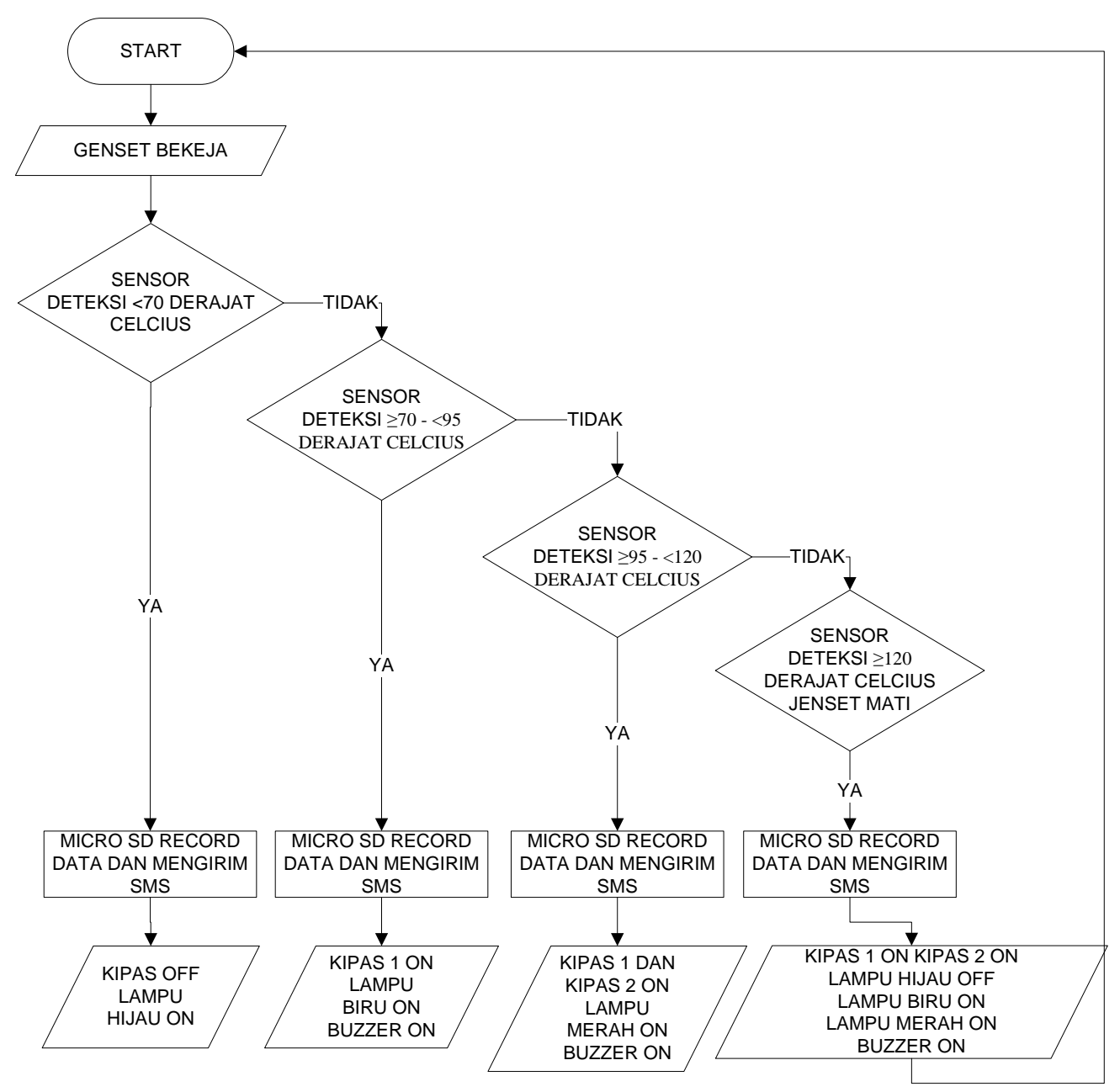

Figure 2. Diagram alur kerja alat 


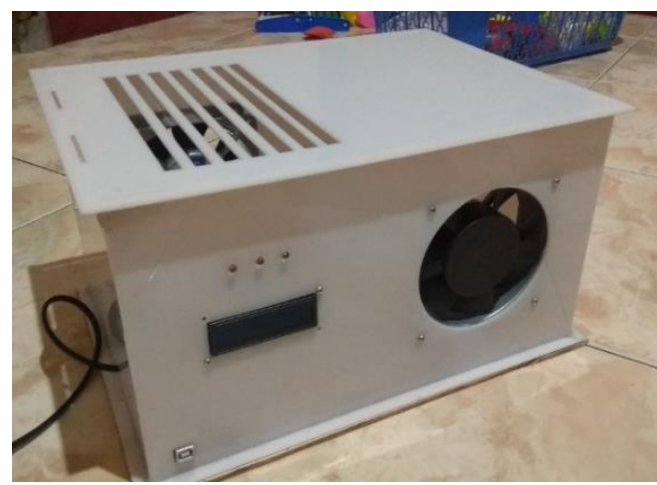

Figure 3. prototype alat

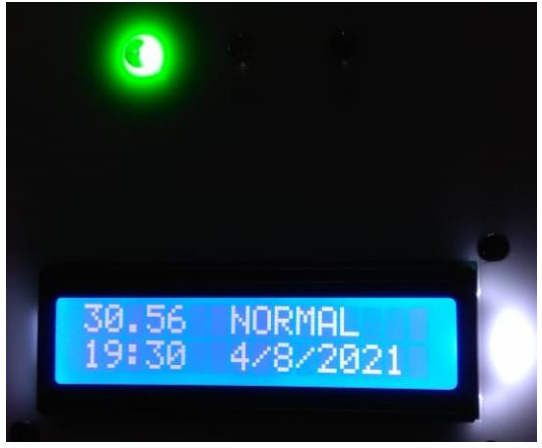

Figure 4. kondisi saat mesin nyala suhu normal di bawah $70^{\circ} \mathrm{C}$

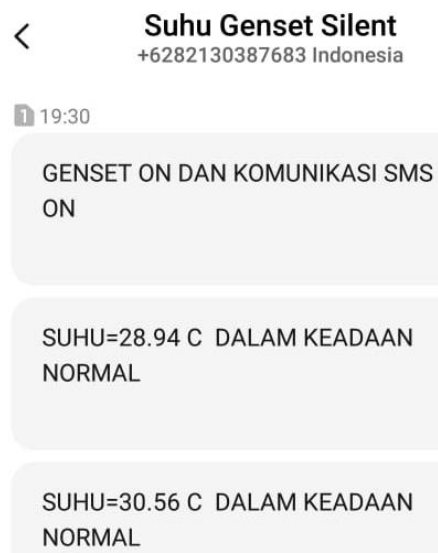

Figure 5. Notifikasi SMS ketika suhu genset normal di bawah $70^{\circ} \mathrm{C}$ 


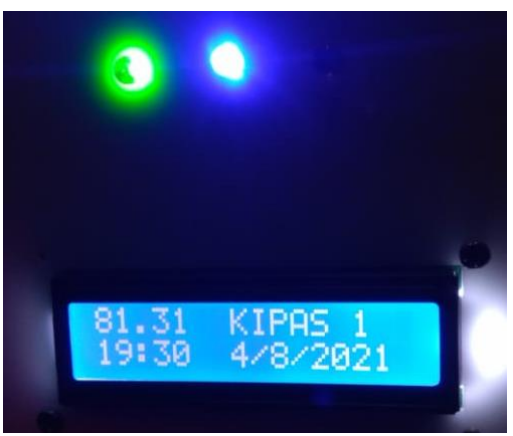

Figure 6. kondisi saat mesin nyala suhu di atas $70^{\circ} \mathrm{C}$

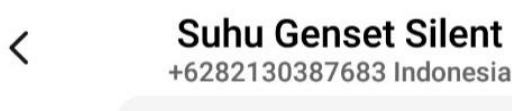

SUHU $=81.31 \mathrm{C}$ KIPAS $1 \mathrm{ON}$

Figure 7. Notifikasi SMS ketika suhu genset di atas $70^{\circ} \mathrm{C}$

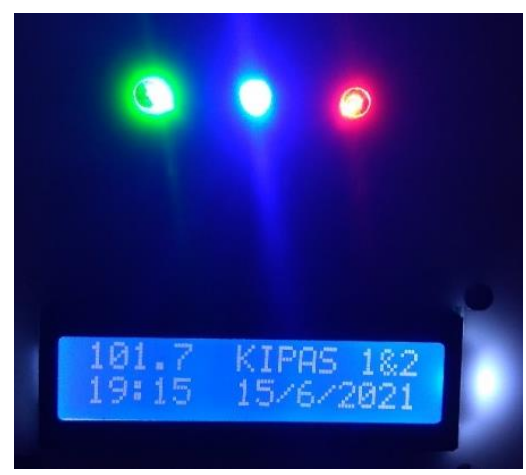

Figure 8. kondisi mesin nyala suhu di atas $95^{\circ} \mathrm{C}$

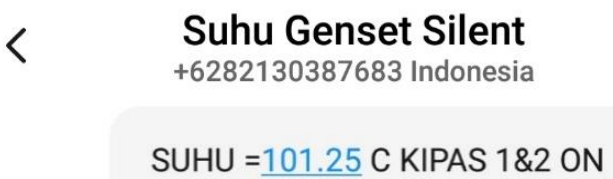


Figure 9. Notifikasi SMS ketika suhu genset di atas $70^{\circ} \mathrm{C}$

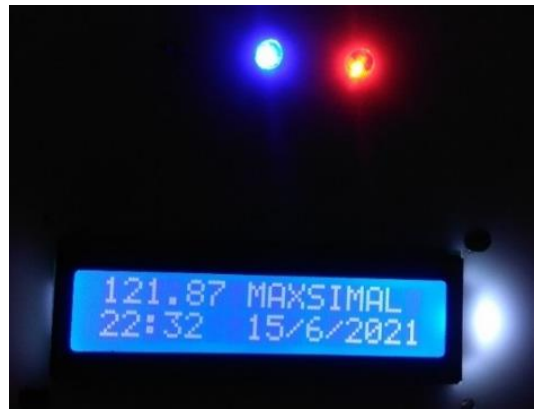

Figure 10. kondisi ketika suhu maksimal $120^{\circ} \mathrm{C}$ mesin dan lampu hijau mati

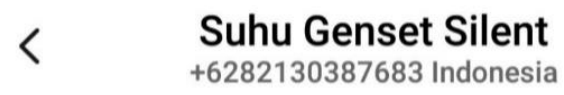

SUHU $=\underline{121.50}$ C OFF GENSET

Figure 11. Notifikasi SMS ketika suhu genset di atas $120^{\circ} \mathrm{C}$ suhu maksimal

\begin{tabular}{|l|l|l|l|l|}
\hline FILE & HOME & INSERT & PAGE LAYOUT & FORMUL. \\
\hline
\end{tabular}

Figure 12. hasil rekam data dari micro SD dengan format CSV 